\title{
Telomere shortening during human septic shock: influence of sepsis mediators, role in organ failures, and septic myocardial dysfunction
}

\author{
Keyvan Razazi ${ }^{1,2^{*}} \mathbb{D}$, Elisabeth Marcos ${ }^{4}$, Sophie Hüe ${ }^{5}$, Laurent Boyer ${ }^{3,4}$, Serge Adnot ${ }^{3,4}$ and \\ Armand Mekontso Dessap ${ }^{1,2,4}$
}

Leucocyte telomere length (LTL) is widely considered a marker of cellular ageing. Telomere attrition has been involved in cardiovascular disorders as a result of inflammatory stress [1], but has been scarcely evaluated in acute settings. Septic shock is associated with an overwhelming inflammatory reaction that may be involved in the genesis of organ failure, including septic myocardial dysfunction [2]. The present study aimed to assess whether septic shock is associated with telomere attrition and evaluate the role of sepsis mediators and the impact on organ failures. Fifty-five patients free of chronic heart failure who met septic shock criteria (as defined according to the ACCP/SCCM Consensus Conference) were prospectively included at the medical intensive care unit of Henri-Mondor University Hospital (Créteil, France).

LTL was measured by QuantStudio ${ }^{\mathrm{TM}} 6$ Flex Real-Time quantitative PCR System (Applied Biosystems, Foster, CA); see Table 1 legend. LTL was assessed in septic shock patients (in 55 and 24 patients on day- 1 and day-2, respectively) and in 55 healthy controls matched to septic shock patients for age ( \pm 3 years) and gender.

Septic myocardial dysfunction (SMD) was defined as a depressed left ventricle ejection fraction $(<45 \%$ or when an inotrope infusion was needed to achieve a

*Correspondence: keyvan.razazi@aphp.fr

${ }^{1}$ Service de Médecine Intensive Réanimation, Hôpitaux Universitaires Henri Mondor, AP-HP, 94010 Créteil, France

Full list of author information is available at the end of the article value $\geq 45 \%$ ) on echocardiography performed on day-1 or day-2 of septic shock [2].

We assessed plasma concentration of 24 putative sepsis mediators on day-1, including inflammatory markers (IL$1 \alpha$, IL-1 $\beta$, IL1-RA, IL-6, IL-10, IL-12, IL-15, IL-17, IL-33, IFN- $\gamma$, TNF- $\alpha$, CD40L, HSP70, sFAS, sFAS ligand, sST2, granzyme, TRAIL, PAI1, and VEGF), chemokines (IL8, MCP1), and adhesion molecules (sVCAM, sICAM). sST2 and the remaining sepsis mediators were measured with human magnetic Luminex screening assay (R\&D, Bio-Techne, Lille, France), and a multi-analyte Milliplex human cytokine kit (Millipore Corporation, Billerica, MA, USA), respectively, and were analyzed using fluorescence intensities [2].

Organ failures and patient severity were assessed using the Sequential Organ Failure Assessment (SOFA) and Simplified Acute Physiology Score II (SAPS II) score, respectively. Spearman bivariate correlations were used to build a focused principal component analysis (FPCA; "psy" package in R), using LTL as the dependent variable and allowing a simple graphical display of correlation structures.

LTL was similar between controls and septic shock patients (Fig. 1a). We observed a correlation between LTL and age in the control group as expected (Spearman's rho $=-0.29, p=0.04$ ) but not in the septic shock group (rho $=-0.03, p=0.82$ ). Table 1 shows the clinical characteristics of septic shock patients according to LTL (below or above median value) on day-1; all original author(s) and the source, provide a link to the Creative Commons licence, and indicate if changes were made. The images or other third party material in this article are included in the article's Creative Commons licence, unless indicated otherwise in a credit line to the material. If material is not included in the article's Creative Commons licence and your intended use is not permitted by statutory regulation or exceeds the permitted use, you will need to obtain permission directly from the copyright holder. To view a copy of this licence, visit http://creativecommons.org/licenses/by/4.0/. The Creative Commons Public Domain Dedication waiver (http://creativeco mmons.org/publicdomain/zero/1.0/) applies to the data made available in this article, unless otherwise stated in a credit line to the data. 
Table 1 Characteristics of patients with septic shock according to leucocyte telomere length at day $1(n=55)$

\begin{tabular}{|c|c|c|c|}
\hline & Lower LTL $(n=27)$ & Higher LTL $(n=28)$ & $P$ value \\
\hline \multicolumn{4}{|l|}{ Clinical characteristics and comorbidities } \\
\hline Age (years) & $64[53-74]$ & $64[49-72]$ & 0.60 \\
\hline Male gender, $n(\%)$ & $20(74 \%)$ & $12(43 \%)$ & 0.02 \\
\hline Chronic obstructive pulmonary disease & $0(\%)$ & $1(4 \%)$ & $>0.99$ \\
\hline Chronic kidney disease requiring long-term dialysis & $2(7 \%)$ & $2(7 \%)$ & 0.97 \\
\hline Liver cirrhosis & $4(15 \%)$ & $3(11 \%)$ & $>0.99$ \\
\hline Mc Cabe and Jackson class & & & 0.49 \\
\hline 0 & $11(39 \%)$ & $12(43 \%)$ & \\
\hline 1 & $10(37 \%)$ & $13(46 \%)$ & \\
\hline 2 & $6(21 \%)$ & $3(11 \%)$ & \\
\hline SAPS II at ICU admission & $50[41-79]$ & 59 [39-79] & 0.83 \\
\hline Community acquired infection & $13(48 \%)$ & $16(57 \%)$ & 0.50 \\
\hline Lung source of infection & $14(52 \%)$ & $13(46 \%)$ & 0.69 \\
\hline Bacteraemia & $11(41 \%)$ & $13(46 \%)$ & 0.67 \\
\hline Surgery & $6(27 \%)$ & $4(16 \%)$ & 0.48 \\
\hline \multicolumn{4}{|l|}{ Organ failures } \\
\hline Sequential organ failure assessment score & $10[8-13]$ & $11[8-13]$ & 0.83 \\
\hline Arterial lactates (mmol/L) & $2.9[1.5-5.5]$ & $2.9[1.4-4.9]$ & 0.87 \\
\hline $\mathrm{PaO}_{2} / \mathrm{FiO}_{2}$ ratio $(\mathrm{mmHg})$ & 164 [115-350] & 188 [109-260] & 0.79 \\
\hline Serum creatinine $(\mathrm{mmol} / \mathrm{L})$ & 201 [84-338] & 164 [84-264] & 0.35 \\
\hline Septic myocardial dysfunction & $10(37 \%)$ & $9(32 \%)$ & 0.70 \\
\hline \multicolumn{4}{|l|}{ Outcome } \\
\hline Mechanical ventilation & $25(93 \%)$ & $24(86 \%)$ & 0.67 \\
\hline Dialysis for acute renal failure & $6(22 \%)$ & $4(14 \%)$ & 0.50 \\
\hline ARDS & $18(67 \%)$ & $13(46 \%)$ & 0.18 \\
\hline ICU acquired infection & $12(43 \%)$ & $9(32 \%)$ & 0.41 \\
\hline Death in ICU & $15(55 \%)$ & $13(46 \%)$ & 0.49 \\
\hline Death in hospital & 15 (55\%) & $16(46 \%)$ & $>0.99$ \\
\hline
\end{tabular}

The telomere repeat copy number to single-gene copy number $(\mathrm{T} / \mathrm{S})$ ratio was determined using the comparative $\mathrm{Ct}$ method $\left(\mathrm{T} / \mathrm{S}=2^{-\Delta \Delta \mathrm{Ct})}\right.$ with $36 \mathrm{~B} 4 \mathrm{gene}$ for normalization (acidic ribosomal phosphoprotein $\mathrm{PO}$, a single-copy gene). Data are number (percentage) or median [first quartile-third quartile]

LTL leucocyte telomere length, SAPS simplified acute physiology score, $\mathrm{PaO}_{2}$ partial pressure of oxygen in arterial blood, FiO $\mathrm{O}_{2}$ fraction of inspired oxygen, ARDS acute respiratory distress syndrome, ICU intensive care unit

variables were similar between groups, except for more female gender in patients with higher LTL. There was no statistically significant correlation between LTL on the one hand and SMD (Fig. 1b), SOFA score, SAPS II score, or sepsis mediators (except for sST2, sFASL and granzyme) on the other hand (Fig. 1c). LTL was similar in septic shock survivors and nonsurvivors at day1 , but decreased between day- 1 and day- 2 in survivors (Fig. 1d).

LTL during septic shock may be determined by factors other than the inflammatory mediators we herein assessed; a prominent role for oxidative stress needs to be assessed in future studies. The association of LTL with FasL is in accordance with a previous study showing a decreased production of FasL after TCR/CD3 signaling of senescent $T$ cells [3]. Senescence was also associated with reduced expression of the effector molecules granzyme and perforin [4]. The decrease in LTL in septic shock survivors may be explained by a relative hyperfunction of leucocyte against infection in this subgroup [5]. We did not find a correlation between LTL and organ failures, as previously reported by Liu et al. [6]. 


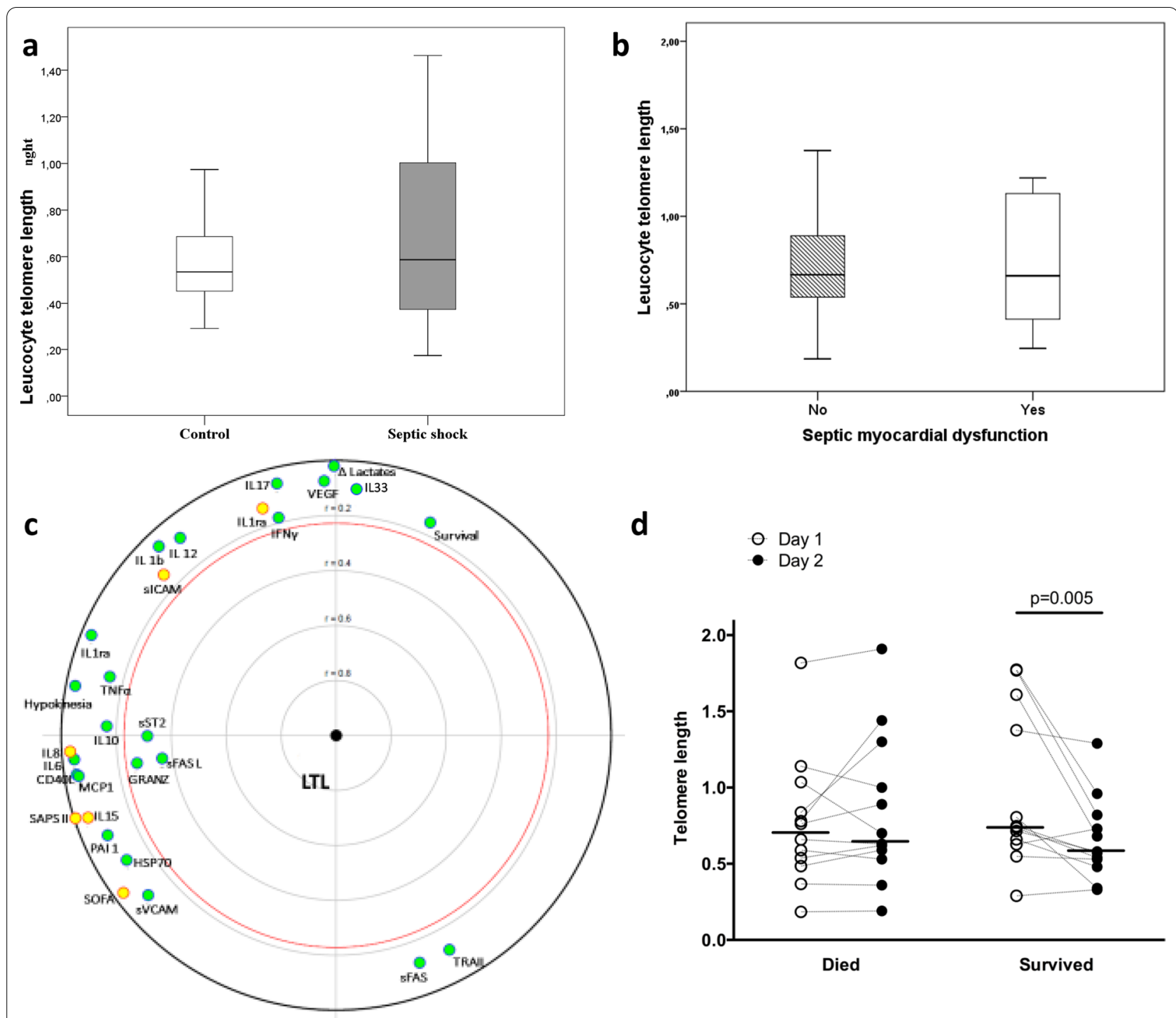

Fig. 1 Leucocyte telomere length in controls and in patients with septic shock (a); LTL in septic shock patients with or without septic myocardial dysfunction (b); Focused principal component analysis (FCPA) for the association between leucocyte telomere length on the one hand, and sepsis mediators, Sequential Organ Failure Assessment (SOFA), Simplified Acute Physiology Score II (SAPS II), lactate clearance ( $\triangle$ lactate) and survival on the other hand (c); LTL at day-1 and day-2 in patients with septic shock according to intensive care unit survival (d). FPCA is a simple graphical display of correlation structures focusing on a particular dependent variable. The display reflects primarily the correlations between the dependent variable and all other variables (covariates) and secondarily the correlations among the covariates. The dependent variable (LTL) is at the center of the diagram, and the distance of this point to a covariate faithfully represents their pairwise Spearman correlation coefficient (using ranked values of continuous variables). Green covariates are positively correlated with the dependent variable. Covariates significantly correlated with the dependent variable (with a $p$ value $<0.05$ ) are inside the red circle. The diagram also shows relationships between covariates as follows: correlated covariates are close (for positive correlations) or diametrically opposite vis-à-vis the origin (for negative correlations), whereas independent covariates make a right angle with the origin

\section{Authors' contributions}

$\mathrm{KR}, \mathrm{EM}$, and $\mathrm{AMD}$ contributed to the study design, analysis and interpretation of data. KR and AMD drafted the initial manuscript and approved the article final version. $\mathrm{KR}, \mathrm{EM}, \mathrm{SH}, \mathrm{LB}, \mathrm{SA}$, and $\mathrm{AMD}$ contributed to the interpretation of data, critical revision of intellectual content and approval of the submitted version of the article. All authors read and approved the final manuscript.

\section{Funding}

No funding was received for this study.

\section{Availability of data and materials}

The datasets supporting the conclusions are included within the article. 


\section{Declarations}

Ethics approval and consent to participate

The study was approved by institutional review board (CPP Ile de France IX).

\section{Consent for publication}

Not applicable.

\section{Competing interests}

All authors report no conflict of interest relevant to this study.

\section{Author details}

${ }^{1}$ Service de Médecine Intensive Réanimation, Hôpitaux Universitaires Henri Mondor, AP-HP, 94010 Créteil, France. ${ }^{2}$ GRC CARMAS, Faculté de Santé de Créteil, IMRB, Université Paris Est Créteil, 94010 Créteil, France. ${ }^{3}$ Département de Physiologie, DHU ATVB, Hôpitaux Universitaires Henri Mondor, AP-HP, Créteil, France. ${ }^{4}$ U955, INSERM, Université Paris Est Créteil, 94010 Créteil, France. ${ }^{5}$ Service d'Immunologie, Hôpitaux Universitaires Henri Mondor, AP-HP, 94010 Créteil, France.

Received: 13 October 2021 Accepted: 8 November 2021

Published online: 18 November 2021

\section{References}

1. Fyhrquist F, Saijonmaa O, Strandberg T. The roles of senescence and telomere shortening in cardiovascular disease. Nat Rev Cardiol. 2013;10:274-83.
2. Razazi K, Boissier F, Surenaud M, Bedet A, Seemann A, Carteaux G, et al. A multiplex analysis of sepsis mediators during human septic shock: a preliminary study on myocardial depression and organ failures. Ann Intensive Care. 2019;9:64.

3. Hsu H-C, Scott DK, Mountz JD. Impaired apoptosis and immune senescence_cause or effect? Immunol Rev. 2005;205:130-46.

4. Yang $\mathrm{OO}$, Lin $\mathrm{H}$, Dagarag $\mathrm{M}, \mathrm{Ng} \mathrm{HL}$, Effros RB, Uittenbogaart $\mathrm{CH}$. Decreased perforin and granzyme B expression in senescent HIV-1-specific cytotoxic T lymphocytes. Virology. 2005;332:16-9.

5. Wang C, Zhang T, Wang Y, Li Y, Liu C, Liu H, et al. The shortening telomere length of T lymphocytes maybe associated with hyper-function in servere aplastic anemia. Mol Med Rep. 2018;17:1015-21.

6. Liu S, Wang C, Green G, Zhuo H, Liu KD, Kangelaris KN, et al. Peripheral blood leukocyte telomere length is associated with survival of sepsis patients. Eur Respir J. 2020;55:1901044.

\section{Publisher's Note}

Springer Nature remains neutral with regard to jurisdictional claims in published maps and institutional affiliations.
Ready to submit your research? Choose BMC and benefit from:

- fast, convenient online submission

- thorough peer review by experienced researchers in your field

- rapid publication on acceptance

- support for research data, including large and complex data types

- gold Open Access which fosters wider collaboration and increased citations

- maximum visibility for your research: over 100M website views per year

At BMC, research is always in progress.

Learn more biomedcentral.com/submissions 